1439

\section{PSYCHOMETRIC PROPERTIES OF ALPE - LANGUAGE TEST (TESTE DE LINGUAGEM- ALPE, TL-ALPE)}

\author{
A. Mendes, M. Lousada, A. Valente, C. Parente, \\ E. Afonso, F. Andrade
}

Instituto de Engenharia Electrónica e Telemática de Aveiro, University of Aveiro, Aveiro, Portugal

ALPE - Language Test (Teste de Linguagem-ALPE, TL-ALPE) is a standardized receptive and expressive European-Portuguese (EP) language assessment instrument of to be used in pre-school age children in order to assess their semantic, morphosyntax and metalinguistic skills development.This paper describes the psychometric properties of TL-ALPE, i.e., - reliability (internal consistency, inter- and intra-judge reliability) and validity (content and construct validity). In order to standardize the TLALPE, 817 children (402 females and 415 males) with ages between [3;0-5;12 [ were assessed across Portuguese mainland and islands. The TL-ALPE was applied by 42 trained and fully licensed SLPs. Preliminary results provided normative data about the EP speaking children: standardized norms (mean, standard deviation and percentile ranks).

Results indicate that TL-ALPE presented a strong cohesion among the items analysed, a strong equivalence between the analysis performed by independent judges, and also a strong stability in the analysis performed by the same judge. Also seems to exist a strong correlation between TLALPE's data and those obtained in other EP studies (construct validity). TL-ALPE adequately measured the child's receptive and expressive language skills (content validity). In conclusion, the analysis of the preliminary results showed that TL-ALPE was a valid and reliable assessment instrument and can be used for early identification of oral language disorders.

Keywords: European-Portuguese, ReceptiveExpressive language, Psychometry, Validity, Reliability

\section{CHILD MORTALITY UNDER FIVE IN LATVIA, CAUSAL RELATIONSHIP AND REDUCTION POSSIBILITIES IN AN INTERNATIONAL CONTEXT}

\author{
I. Ebela, I. Daugule, I. Rumba-Rozenfelde \\ Faculty of Medicine, University of Latvia, \\ Riga, Latvia
}

Background and aims: To identify the reasons of the continuously highest infant and under five mortality $(\mathrm{U} 5 \mathrm{M})$ rates in Latvia (since restoration of independence) within EU - 25, in order to find solutions to minimize the mortality rate in accordance with Millenium Development Goals (MDG).

Methods: Analytical study of statistical data bases was performed by monitoring reports, private publications to find causal relationship in international aspect between U5M in Latvia and following factors: GDP, health budget per capita, Gini coefficient, medical service availability, etc.

Results: Structure of U5M in Latvia differs from EU-25, being 2 to 10 times higher by reason of external causes of death. Incidence of sudden infant death syndrome, infant mortality caused by developmental disorders and in-born abnormalities are also noticeably higher.

Conclusions: Mistakes in state policy regarding health issues are obvious since the regaining of independence. Availability of medical services covered by state health insurance was extremely decreased for population of Latvia compared to Baltic neighbouring countries. Gini coefficient is among the highest within EU-25 whereas health budget per capita as percentage of GDP is the lowest one by purchasing ability. This places Latvia in marginal position of industrialized countries of European region. Political will volition is decisive to diminish $U 5 \mathrm{M}$, by providing adequate percent of GDP for health budget, sufficient access to medical care via social inclusion, health insurance, public campaigns preventing SIDS, external death causes and advertising importance of early ultrasound diagnostics. 